\title{
DESAFIOS DO PROFESSOR NA PROMOÇÃO DA APRENDIZAGEM BASEADA NO MÉTODO DO ESTUDO DE CASO
}

\author{
Jaime José Rauber ${ }^{1}$
}

\begin{abstract}
Resumo: $\mathrm{O}$ estudo de caso, como método de aprendizagem, torna o estudante sujeito ativo e personagem principal do processo educacional. Nele, porém, o professor desempenha papel fundamental, pois deve atuar como estrategista para que a construção de conhecimentos e o desenvolvimento de habilidades aconteçam da melhor forma possível. Com base numa reflexão sobre a própria prática, o objetivo do presente estudo consiste na apresentação de alguns desafios do professor que adota o estudo de caso como método para a promoçáo da aprendizagem a partir de uma experiência realizada numa disciplina de Ética no nível da graduação. Os resultados mostram que o método apresenta grandes vantagens em relação ao ensino tradicional, mas requer atenção do professor em relação a diferentes aspectos que podem interferir nos resultados da aprendizagem desejada.
\end{abstract}

Palavras-chave: Disciplina de Ética. Processo Ensino-aprendizagem. Metodologias Ativas.

\section{TEACHER'S CHALLENGE ON PROMOTE LEARNING BY CASE STUDY}

\begin{abstract}
Case study, as a learning methodology, become the student an active subject and main character of the educational process. However, teacher plays a fundamental role, since it must act as a strategist in order the construction of knowledge and skills development happens in the best possible way. Based on a reflection on the practice itself, the aim of the present study was, from an experience in an Ethics discipline at the undergraduate level, to show some teacher's challenges when using case study as a method to promote learning. The results showed that method have great advantages in relation to traditional education, but it requires teacher attention regarding different aspects that may interfere in the desired learning outcomes.
\end{abstract}

Keywords: Ethics Discipline. Teaching-learning Process. Active Learning Methodologies.

1 Doutor em Filosofia (UFSCAR) e Professor do Eixo Humanístico da PUCPR - Câmpus Toledo. E-mail: <jaime.rauber@pucpr.br>. 


\section{INTRODUÇÃO}

A disciplina de Ética está presente em grande parte dos cursos ofertados por Instituições de Ensino Superior. Algumas delas entendem a formação ética como um princípio educacional e, por conseguinte, a disciplina assume lugar privilegiado nas matrizes curriculares dos cursos ofertados. Outras limitam-se a cumprir as exigências das diretrizes curriculares nacionais dos respectivos cursos. Mais do que um simples cumprimento legal, a qualidade da educação proporcionada por uma instituição de ensino é medida também pelo seu compromisso com a dimensão ética. Paviani (1998) afirma que o ensinar e o aprender, que são processos e não produtos, só têm qualidade quando assumem sua condição ética. Compreensão semelhante tem Echeverría-Falla quando afirma que "a educação ética constitui a primeira responsabilidade social da universidade e dos docentes universitários" (2013, p. 154). Dentro desta perspectiva, não basta a presença da disciplina de Ética nas matrizes curriculares, é necessário que todo o processo educacional seja mediado por princípios éticos.

Seja por exigência legal ou por princípio educacional, o desenvolvimento da aprendizagem na disciplina de Ética acaba sempre sendo um dilema para o respectivo professor. Por um lado, tem-se a compreensão de Aristóteles (1992) de que as virtudes morais não podem ser ensinadas, mas que vão se desenvolvendo nos indivíduos por meio do hábito e da prática de ações boas. Por outro, tem-se o desafio de transformar os estudantes em sujeitos melhores no sentido ético, dignos de receberem o "diploma de gente boa"’. Esta afirmação sugere que a ética pode ser ensinada e que a universidade tem papel importante na construção do modo de ser ético dos estudantes. A compreensão de que a universidade tem o dever de preparar os jovens para receberem o "diploma de gente boa" não faz apologia à ideia de que as virtudes éticas podem e devem ser ensinadas, mas que a universidade não pode ficar alheia à formação ética e humanística dos sujeitos que a procuram. Segundo Juliatto, a educação não deve ocupar-se apenas com o conhecimento, mas também com a formação para a sabedoria, pois "o conhecimento oferece recursos

2 O autor agradece o suporte financeiro do FINEP e o apoio do CREARE (PUCPR) para a implementação da prática e realização da pesquisa.

3 Expressão muito usada pelo Ex-Reitor da PUCPR Ir. Clemente Ivo Juliatto que, em discursos dirigidos à comunidade acadêmica, dizia que a instituição têm o desafio de formar profissionais que sejam dignos de receber dois diplomas: o de profissionais altamente preparados e competentes em suas áreas específicas de formação, e o "diploma de gente boa", referindo-se à formação humanística e ética a ser proporcionada aos estudantes durante o seu percurso acadêmico na PUCPR. 
necessários para o fazer, que é o domínio da técnica" enquanto que a sabedoria "ensina a agir, isto é, a dominar o campo da ética" (2009, p. 44). ${ }^{4}$

Em conformidade com o pensamento de Aristóteles (1992), no presente artigo parte-se da compreensão de que o agir ético de fato não pode ser ensinado e que o agir virtuoso depende da prática de ações boas, ou seja, do hábito de fazer o bem. Cabe ao professor da disciplina de Ética, portanto, preocupar-se não com o ensino das virtudes morais (éticas), uma vez que essas não podem ser ensinadas, mas com a aprendizagem relacionada ao desenvolvimento das virtudes intelectuais (dianoéticas) de modo que os estudantes tenham clareza sobre a natureza da ética e aprendam por meio da deliberação a fazer escolhas que de fato visem o bem de todos os possíveis concernidos, seja no ambiente profissional ou não profissional. De modo semelhante, Gomez e Royo afirmam que a formação ética no mundo universitário não deve limitar-se à transmissão de um conjunto de saberes, mas "deve supor uma aprendizagem prática vivida na cotidianidade da vida do estudante que combine, na construção da sua forma de ser, pensar e conviver, critérios de felicidade pessoal com critérios de solidariedade e cuidado com os demais" (2015, p 348).

Dentro desta perspectiva, a discussão sobre o ensino da ética deve focarse não na transmissão de valores ou virtudes éticas, mas no desenvolvimento da sabedoria prática (virtude intelectual), isto é, da capacidade de análise, reflexão, deliberação e tomadas de decisão sobre dilemas éticos em situações de contexto real. Goergen (2001, p. 153) afirma que a educação moral não serve para internalizar de forma mecânica normas consideradas corretas, mas deve ser um "processo de familiarização com um discurso moral a partir de princípios gerais, na sua interface com circunstâncias concretas". As teorias éticas, sustentadas em concepções filosóficas, assumem o papel de princípios gerais e modelos teóricos a partir das quais os problemas éticos do cotidiano podem ser discutidos.

Diferentemente do ensino tradicional focado na transmissão de conhecimentos e valores considerados corretos dentro de um determinado contexto histórico ou modelo filosófico, o ensino da ética baseado no método de estudo de caso visa transformar o estudante em sujeito ativo no processo ensino aprendizagem por meio do qual desenvolve habilidades imprescindíveis para tomadas de decisão racionalmente motivadas em situações de contexto real. Entretanto, a adoção do estudo de caso como método de aprendizagem traz alguns desafios para o professor. É dentro desta perspectiva que se encontra o problema norteador do presente artigo: Quais as dificuldades do professor da disciplina de Ética na promoção da aprendizagem baseada em estudo de casos?

4 Com raciocínio semelhante, Zetina e Pinon (2017, p.86) afirmam que a sociedade não deve se preocupar apenas com a busca da riqueza nem querer que as escolas formem pessoas cujo único objetivo é gerar renda financeira, pois seu papel é formar pessoas reflexivas e razoáveis. Destacam ainda que a educação não deve focar-se tanto nas carreiras tecnológicas e de negócios, pois a área de humanidades traz "disciplinas fundamentais para preservar a saúde da sociedade e do nosso mundo" (ZETINA; PINON, 2017, p.86). 
A pesquisa não consiste num relato de sucesso da aplicação do estudo de caso como método de aprendizagem numa disciplina de Ética, mas numa reflexão sobre a própria prática tomando como base os registros feitos no diário de bordo. Como se trata de uma primeira experiência com a abordagem do método de caso, o texto traz mais oportunidades de melhorias da própria prática do que orientações sobre como trabalhar o estudo de caso a partir de relatos de sucesso.

$\mathrm{O}$ artigo apresenta inicialmente algumas características gerais do método de estudo de caso com base em diferentes autores. Num segundo momento apresenta o encaminhamento metodológico da aplicação do estudo de caso em uma disciplina de Ética num curso de graduação. E, por fim, serão apresentados os resultados e discussões da experiência realizada tendo como norte o problema de pesquisa apresentado.

\section{$2 \mathrm{O}$ estudo de caso como método de aprendizagem}

O estudo de caso como abordagem de ensino foi empregado inicialmente na faculdade de Direito da Universidade de Harvard, por volta de 1870, com o objetivo de preparar os estudantes para a realidade da vida profissional (SILVA; BENEGAS, 2010). Pelo sucesso alcançado no meio jurídico, esse método também foi adotado na faculdade de Administração da mesma universidade a partir de 1910 (SILVA; BENEGAS, 2010). A Harvard Business School é, segundo Silva e Benegas (2010) a maior produtora de casos do mundo, seguida pela faculdade de Administração da University of Western Ontário, do Canadá, que produz em torno de 500 casos por ano.

Segundo Ellet (2008), não é possível escrever-se uma teoria sobre o método do estudo de caso, pois os casos revelam o que acontece no mundo real com situações bem particulares e com uma lógica própria. Golich et al. (2000) afirmam que querer escrever um bom livro sobre o método de casos é algo muito pretensioso. Nesse sentido, na obra The $A B C$ s of Case Teaching limitam-se a apresentar diretrizes para serem adaptadas no processo ensino aprendizagem, pois existem muitas variantes envolvidas no método de caso de modo que não há orientação única e fechada sobre como adotá-lo. O que existe, segundo os autores deste livro, são orientações e diretrizes comuns que não podem ficar de lado no método de caso. É por meio da prática de sala de aula que se aprende os fundamentos do processo ensino aprendizagem baseado em casos (GOLICH et al., 2000).

Os casos são narrativas sobre situações de contexto real e que colocam o leitor como participante da situação visando buscar uma resposta para determinado problema significativo (ELLET, 2008). O tamanho dos casos podem variar de alguns parágrafos até descrições de mais de cinquenta páginas. O tamanho da narrativa não determina a qualidade do caso. Um caso pode ser curto, mas deve "representar a realidade, descrever uma situação com todos os fatos transversais e delimitações - incluindo impropriedades, questões secundárias, falsos juízos e informações incompletas" (ELLET, 2008, p. 21). Os casos descrevem situações de contexto real que abrigam incertezas, lidam com casualidades e nem sempre apresentam as informações de modo ordenado e detalhado. De modo análogo ao 
que acontece em situações complexas do mundo real, o estudante é desafiado a tomar decisões mesmo não tendo acesso a todas as informações que gostaria de ter.

Ellet (2008, p.21) afirma que um bom caso deve apresentar características básicas, ou seja, deve trazer uma questão significativa, informações suficientes que permitam a extração de conclusões e não deve apresentar conclusões manifestas. Diferentemente deste autor, Silva e Benegas (2010, p. 19) entendem que, além dos casos-problema, de solução aberta e sem conclusões manifestas, há também os casos-exemplo, que são de solução fechada. Os casos-problema apresentam uma narrativa acompanhada de um problema central sem apresentar uma solução para o caso. Os estudantes, nestes casos, são desafiados a encontrarem uma solução própria para o problema a partir das informações contidas no relato. Os casosexemplo, por sua vez, apresentam uma narrativa com solução fechada. Por meio deles relata-se o que já aconteceu em determinada empresa ou situação e os estudantes são desafiados a discutirem se a solução apresentada foi adequada ou não e que outras alternativas poderiam ser apresentadas.

Segundo Silva e Benegas (2010), as narrativas devem apresentar uma mistura de arte e técnica para tornar o estudo de caso atraente e produtivo. Os casos descrevem eventos do mundo real para o qual os estudantes precisam apresentar uma solução ou avaliar se a solução apresentada é adequada ou não com base em bons argumentos. O estudo de caso, como método de aprendizagem, tornouse muito útil para a formação de futuros profissionais, pois a apresentação de narrativas que descrevem fenômenos do mundo contemporâneo antecipam "o estudo de realidades que o aluno viverá nos inúmeros empreendimentos que estiver à frente" (SILVA; BENEGAS, 2010, p. 12).

Golich et al. (2000) afirmam que os casos não precisam ser necessariamente narrativas, mas podem ser recortes de fenômenos do mundo real compartilhados com os estudantes e que os obriga a chegarem a um acordo sobre determinado problema visto a partir de múltiplas perspectivas. Como exemplos os autores citam uma pilha de destroços de um acidente de avião, um sistema de cavernas de calcário num aquífero ocidental, ou um pedreiro velho com dores no peito. A esses fenômenos acrescentam respectivamente os seguintes problemas: "O que causou o acidente? Como essas cavernas foram formadas? E por que esse homem está sofrendo de falta de ar e constrição dos músculos do tórax?” (GOLICH et al., 2000, p.12). Reis (2007) afirma que os casos também podem ser preparados a partir de diferentes materiais, como artigos de jornais e de revistas, livros, programas de televisão, filmes e cartoons. Os casos, portanto, podem ser de diferentes naturezas e preparados a partir de diferentes materiais, mas precisam girar em torno de um problema central com um objetivo de aprendizagem claramente definido para transformar a sala de aula num espaço de debate de ideias, desenvolvimento de habilidades e construção de conhecimentos.

As soluções para os problemas levantados em casos podem ser apresentadas a partir de uma discussão evolvendo a turma toda, pequenos grupos ou mesmo 
a partir de reflexões individuais (ELLET, 2008, p. 14). No estudo de caso os estudantes são estimulados a desenvolverem dois conjuntos de habilidades, quais sejam, a capacidade de analisar o caso buscando soluções coerentes, e a capacidade de comunicar seu pensamento com eficiência, seja de modo oral ou por escrito (ELLET, 2008, p. 14). As discussões em torno de um determinado problema exige que o estudante assuma uma posição e manifeste seu ponto de vista para a apreciação dos colegas do grupo ou da turma como um todo. Esse posicionamento exige que o estudante seja autor e membro ativo do processo ensino aprendizagem.

O método de caso é uma abordagem que se opõe ao modelo tradicional focado na transmissão de conhecimentos e que mantém o estudante passivo no processo educacional. Segundo Dewey (citado por ZETINA; PINON, 2017, p.86) o problema central dos métodos tradicionais é a passividade provocada nos estudantes. No modelo tradicional, as salas de aula são compreendidas como espaços para ouvir e absorver conteúdos, jamais priorizam a análise, a investigação e a resolução de problemas. Embora as aulas expositivas permitam a transmissão de grande quantidade de informações num curto espaço de tempo e para uma grande quantidade de pessoas, os ouvintes, de modo geral, não são estimulados a pensar acerca desse conteúdo nem a aplicá-lo (ELLET, 2008, p.15). No método de caso, o estudante é colocado no centro do processo educacional. Ele torna-se o principal responsável pela sua própria aprendizagem. "O instrutor não é mais uma máquina de caixa automática vomitando fatos e teorias, mas o maestro da orquestra tentando extrair o melhor de cada estudante" (GOLICH et al., 2000, p. 4). Neste contexto, o professor torna-se responsável por tentar extrair o melhor de cada membro da classe visando a produção coletiva de conhecimentos. Por consequência, os estudantes se sentirão coautores, reconhecidos e valorizados no processo de busca da verdade. Em aulas expositivas os estudantes apenas recebem conhecimentos de um especialista enquanto que por meio do estudo de caso eles produzem conhecimentos com o auxílio do professor (ELLET 2008, p. 15).

O método de caso é muito útil para o desenvolvimento de habilidades exigidas pelo atual mercado profissional. A capacidade de pensar com clareza, de organizar o raciocínio de forma lógica e de comunicar-se de modo convincente constituem importantes habilidades para líderes e administradores (ELLET, 2008, p.16). Saber ouvir e fazer-se ouvir durante uma discussão revela a importância do indivíduo e desenvolve habilidades de trabalho em equipe na solução de problemas (SILVA; BENEGAS, 2010, p. 16).

Em função dos seus múltiplos significados, os casos são sempre controversos de modo que "numa turma com quarenta estudantes, por exemplo, é provável que haja quarenta pontos de vista sobre o mesmo caso" (ELLET 2008, p. 16). Não obstante isso, se há um problema a ser resolvido e quarenta pontos de vista diferentes, não é possível que essas diferentes teses sejam todas igualmente defensáveis. Assim, para solucionar as controvérsias em torno de determinado problema, é preciso fazer uso da capacidade de argumentação e persuasão para convencer os interlocutores sobre determinada tese: "A argumentação e a persuasão são necessárias para resolver controvérsias - para ajudar pessoas com diferentes 
pontos de vista sobre o mesmo assunto a chegar a um consenso" (ELLET, 2008, p.16). Nesse sentido, cabe ao emissor analisar uma situação de modo preciso e fazer uso de argumentos racionalmente motivados para persuadir os ouvintes sobre sua tese mediante apresentação de evidências. Embora no estudo de caso não se tenha uma resposta única e absoluta sobre o problema apresentado, o mesmo requer uma resposta plausível sustentada nos melhores argumentos. Todos os participantes do estudo de caso são corresponsáveis pelos resultados da discussão e por isso não podem permitir que apelos emocionais, argumentos de autoridade e falácias interfiram nas conclusões do grupo.

No estudo de caso, os professores, por mais que sejam especialistas no assunto, jamais devem transmitir seu conhecimento de forma direta (ELLET, 2008, p.19). O grande desafio do professor consiste em fazer perguntas certas no momento certo gerando um debate permeado de significado e conteúdo aos estudantes tendo em vista a solução de determinado problema. Diferentemente de que acontece em aulas expositivas, nas quais o professor é a grande fonte de informações, no estudo de caso o conteúdo dos debates é fornecido pelos estudantes, que devem participar ativamente e de modo qualitativo nas discussões do grupo (ELLET, 2008, p.19). A sala de aula não lida mais com apenas uma verdade transmitida pelo professor, mas com diferentes interpretações e possibilidades de soluções para determinada questão construídas junto com os estudantes. Os professores podem até contribuir com a compreensão de conceitos para analisar casos, mas não devem jamais anunciar "conclusões definitivas ou respostas certas, ainda que possam discriminar entre soluções mais ou menos plausíveis" (ELLET, 2008, p.20).

No método de caso, o papel do professor é fundamental, embora não seja ele o principal responsável pela aprendizagem dos estudantes. Semelhante ao papel do maestro numa orquestra, o trabalho do professor é essencial para se alcançar a excelência no processo ensino aprendizagem (GOLICH etal al., 2000, p. 4). O professor ajuda os estudantes a produzirem os melhores resultados individualmente e a trabalharem coletivamente. Individualmente são estimulados a desenvolverem habilidades de análise e de comunicação; coletivamente são desafiados pelo professor a encontrarem uma solução sustentável para o problema central do caso. No método de caso os estudantes desenvolvem habilidades de análise, comunicação e colaboração porque são ferramentas necessárias para desvendar o quebra-cabeça do caso (GOLICH et al., 2000, p. 4)

$\mathrm{Na}$ condução das discussões em estudos de caso o professor deve adotar o método socrático. "O método socrático baseia-se na investigação e dialética para analisar e buscar a verdade, questionar tudo o que é conhecido ou assimilado, eliminar as pretensões de certeza e procurar detalhes para alcançar um entendimento geral ou uma compreensão mais profunda sobre determinado tema" (ZETINA, PINON, 2017, p.84). Adotando uma postura socrática, o professor não se apresenta como dono da verdade nem se encontra no centro do processo ensino aprendizagem, pois figura apenas como estrategista que, por meio de perguntas adequadas e em momentos oportunos, faz os próprios estudantes gerarem o conhecimento mediante a autoanálise e confrontação de ideias. Esse modo de 
proceder é conhecido como maiêutica socrática, que Reale sintetiza da seguinte maneira: "da mesma forma que a mulher que está grávida [...] tem a necessidade da parteira para dar à luz, também o discípulo que tem a alma grávida de verdade tem necessidade de uma espécie de arte obstétrica espiritual que ajude essa verdade a vir à luz" (1990, p. 99). De modo análogo, não é o professor que gera, transmite, ou dá luz às ideias, mas é ele quem, na função de parteiro de ideias, auxilia os estudantes na tarefa de trazer a verdade à luz.

Exposto em linhas gerais em que consiste o método do estudo de caso, suas especificidades em relação ao modelo educacional tradicional e respectivo papel do professor, na sequência serão apresentados os encaminhamentos metodológicos da prática de sala realizada para, por fim, apresentar os resultados e discussões sobre a própria experiência no que diz respeito aos desafios do professor na aplicação do método de caso numa disciplina de Ética.

\section{Encaminhamento metodológico}

Partindo da compreensão de que não se pode "conceber um professor que não se questione sobre as razões subjacentes às suas decisões educativas, que não se questione perante o insucesso de alguns alunos, que não faz dos seus planos de aula meras hipóteses de trabalho a confirmar ou infirmar no laboratório que é a sala de aula" (ALARCÃO, 2001, citado por PONTE, 2002, p.6), o foco principal da presente pesquisa consiste numa reflexão sobre a prática da aplicação do método de estudo de caso numa disciplina de Ética num curso de graduação de uma universidade do Paraná. A coleta de dados se deu numa turma do terceiro período do curso de Psicologia. A turma era composta por 38 estudantes, dos quais 28 eram do curso de Psicologia e 10 eram de outros cursos da instituição. Os encontros aconteceram no período noturno, com duas horas aula semanais, ao longo de um semestre.

Visando suprimir aulas predominantemente expositivas e buscando desenvolver saberes e habilidades por meio de métodos que promovam a aprendizagem ativa, a disciplina foi planejada com a aplicação de duas metodologias (TBL - Team Based Learning e o Estudo de Caso) e algumas técnicas de aprendizagem ativa visando uma maior dinamização das aulas. O TBL foi aplicado em cinco encontros do primeiro bimestre para a compreensão de conceitos centrais da ética geral sem fazê-lo por meio de aulas expositivas. O estudo de caso foi aplicado em quatro encontros do segundo bimestre visando desenvolver a capacidade de tomada de decisões em situações de contexto real mediante a análise de casos. Outros sete encontros foram utilizados para apresentação do Plano de Ensino, aplicação de avaliações somativas e formativas com feedbaks entre pares e individuais bem como estudo de teorias morais por meio da aplicação de técnicas que facilitam a promoção da aprendizagem ativa.

Os estudos de caso foram realizados por meio de análises primeiramente individuais, depois em times e, por último, com discussões envolvendo toda a classe. A composição dos times para a realização dos estudos de caso ficou a 
mesma empregada na aplicação da metodologia TBL. Os times foram compostos a partir da aplicação de um questionário com perguntas sobre idade, cidade onde mora, se está ou não empregado, a quanto tempo concluiu o ensino médio, curso que realiza, se segue ou não uma religião, se tem facilidade de expor suas ideias em público e se considera ter ou não perfil de liderança. Com base nessas informações, o professor da disciplina distribuiu os estudantes em seis times (4 grupos com 6 estudantes e 2 grupos com 7) procurando deixá-los ecléticos o máximo possível. Nos encontros que antecederam a aplicação do método de caso, buscou-se fazer um estudo sobre fundamentos teóricos da ética para evitar posicionamentos de senso comum, dogmáticos ou relativistas em relação aos problemas levantados nos casos apresentados.

A coleta de dados sobre a prática desenvolvida se deu mediante registros num diário de bordo realizados imediatamente após cada encontro para não se perder informações relevantes. Ao todo foram feitos registros de 16 encontros, com média de uma página e meia de anotações digitadas ${ }^{5}$ por encontro, contemplando aspectos como: a) o que planejei alcançar nesta aula e como planejei alcançar estes resultados; b) quais lacunas que ficaram entre o que eu planejei e de fato aconteceu na aula e qual foi a reação dos estudantes; c) o que eu aprendi sobre mim mesmo, meus estudantes e sobre o processo ensino aprendizagem; d) quais são meus pontos fortes em relação ao planejado e ao que aconteceu em aula ${ }^{6}$.

A análise dos dados coletados se deu a partir da releitura dos registros nos diários de bordo com ênfase nos encontros nos quais foi adotado o método de estudo de caso para a promoção da aprendizagem dos estudantes. A partir da análise desses registros foram extraídos os resultados que seguem.

\section{Resultados e discussão}

Acostumado a ministrar aulas predominante expositivas, o desafio para a disciplina de Ética foi planejá-la de modo que os estudantes pudessem se tornar sujeitos ativos no processo ensino aprendizagem. Em aulas expositivas, os estudantes ficam limitados aos níveis cognitivos mais baixos (lembrar e entender) da taxonomia de Bloom (FERRAZ; BELHOT, 2010). Com a proposta de adoção de métodos para a promoção da aprendizagem ativa, buscou-se transformar a sala de aula num espaço no qual os estudantes pudessem alcançar níveis cognitivos mais elevados (aplicar, analisar, avaliar e criar). Mais do que simplesmente conhecer e compreender conteúdos de ética, partiu-se do princípio de que durante a disciplina os estudantes devem aprender a aplicar os conhecimentos gerados por eles na interação com os colegas e o professor, analisar os diferentes aspectos envolvidos num

5 Anotações digitadas em fonte Arial tamanho 12, espaçamento entrelinha 1,5.

6 Este roteiro para os registros no diário de bordo foi indicação do Centro de Ensino e Aprendizagem (CREARE) da PUCPR, cujo apoio durante toda a prática realizada foi de fundamental importância. 
determinado problema, avaliar vantagens, desvantagens e possíveis consequências de escolhas feitas e criar planos alternativos de ação em situações de contexto real visando a promoção do bem de todos os possíveis concernidos.

A partir de um redesenho da disciplina de Ética, definiu-se que ao final dela os estudantes deveriam ser capazes de tomar decisões éticas com base em razões passíveis de serem sustentadas argumentativamente. Para alcançar tal objetivo, optou-se pelo emprego do TBL e do estudo de caso como métodos predominantes para a promoção da aprendizagem no decorrer da disciplina. Por se tratar de uma disciplina que integra o Eixo de Formação Humana ${ }^{7}$, a escolha do método TBL deu-se também com o objetivo de desenvolver os princípios da graduação preconizados pela instituição, quais sejam: autonomia, dedicação, honestidade, cooperação e senso crítico (PUCPR, 2014). O TBL é, certamente, um dos métodos mais completos para desenvolver estes cinco princípios. Por meio da necessidade do estudo prévio e discussão de ideias no time, desenvolve-se a autonomia e o senso crítico; a preparação prévia às aulas com leitura de pequenos textos ou vídeos, exige força de vontade e dedicaşão por parte do estudante; a honestidade é posta em prática de modo especial no preenchimento do gabarito, tanto nos testes de resposta individuais (iRAT) quanto nas respostas do time ( $t \mathrm{R} A T)$; e, por último, a cooperação é desenvolvida no confronto das ideias e escolha da resposta do time, momento no qual os pares são desafiados a cooperarem uns com os outros na busca do consenso ou da alternativa mais adequada em torno de determinado problema. ${ }^{8}$

Com o objetivo de desenvolver nos estudantes a capacidade de tomarem decisões éticas com base em argumentos sustentáveis racionalmente, escolheu-se o estudo de caso como método de aprendizagem. Se o TBL exige o confronto de ideias, a cooperação entre os pares e a escolha de uma resposta comum do time nas questões apresentadas, o estudo de caso coloca os estudantes frente a situações complexas de contexto real e exige que tomem decisões sustentando seus posicionamentos com base em argumentos possíveis de serem aceitos pelos colegas de time e pela classe como um todo. O estudo de caso por natureza apresenta situações de contexto real e isso o torna um método privilegiado para os estudantes aprenderem a tomar decisões levando em conta diferentes contextos, situações e sujeitos envolvidos. O estudo de caso antecipa recortes de situações do mundo real para os quais os estudantes, como futuros profissionais ou simplesmente como cidadãos do mundo, precisam tomar decisões racionalmente motivadas, ou seja, passíveis de serem aceitas universalmente.

7 O Eixo de Formação Humana da PUCPR contempla as disciplinas de Filosofia, Ética, Cultura Religiosa e Projeto Comunitário.

8 O desenvolvimento dos princípios da graduação são de suma importância para a aplicação do estudo de caso como método para a promoção da aprendizagem aos estudantes: a dedicação é fundamental para a realização de atividades prévias, a autonomia para pensar alternativas de ação e respectivas consequências, a cooperação entre pares para buscar uma resposta para o problema central do caso, a honestidade para argumentar seriamente em torno de posicionamentos assumidos e o senso crítico para distinguir e aceitar apenas argumentos racionalmente motivados. 
O estudo de caso, porém, apresenta alguns desafios para o professor, principalmente quando é adotado como método para a promoção da aprendizagem ativa num contexto no qual os estudantes e o próprio docente estão acostumados com aulas predominantemente expositivas. Tomando como base a experiência realizada em sala de aula e os registros dos diários de bordo foi possível identificar alguns desafios da aplicação do método por parte do professor.

a) Motivação dos estudantes para atividades prévias. A motivação dos estudantes para a realização de atividades previas é um dos grandes desafios para o professor. Por se tratar de uma primeira experiência com o estudo de caso, optou-se pela aplicação de casos mais curtos, porém intercalados com o estudo de diferentes modelos éticos da tradição filosófica. O objetivo desta proposta de trabalho foi conhecer em linhas gerais três teorias éticas e aplicar seus conceitos e princípios na resolução de casos propostos. Os autores escolhidos foram Aristóteles, Kant e Hans Jonas. Sabendo da dificuldade de fazerem leituras prévias de textos longos e mais ainda quando se trata de textos da tradição filosófica, para cada teoria moral foi indicada leitura obrigatória de uma síntese de até três páginas sobre a teoria moral do autor. Pesquisas e leituras complementares também foram recomentadas para que os estudantes pudessem ter uma compreensão maior da teoria moral em estudo. Em encontro presencial, com um conjunto de questões orientadoras disponibilizadas pelo professor, cada time foi desafiado a debatê-las com base nos estudos prévios realizados. Entretanto, constatou-se que boa parte dos estudantes não cumpriu a tarefa, o que dificultava a compreensão dos conceitos mesmo com a discussão em pares. Isso resultou em elevado número de solicitações de intervenção do professor nos times para ajudar no esclarecimento de conceitos. Como a ideia não era fazer uma exposição dos conceitos, pois isso levaria novamente a aulas expositivas, o atendimento às solicitações dos times ficou comprometido pelo fator tempo. Com base no constatado, foi solicitado maior empenho dos estudantes nessa tarefa. Mesmo tendo percebido uma pequena melhora nesse aspecto em encontros posteriores, ainda ficou evidenciada a falta de um empenho maior por parte dos estudantes.

A realização de atividades prévias é imprescindível em praticamente todos os métodos que promovem a aprendizagem ativa. Há várias estratégias possíveis para se garantir que as atividades prévias sejam realizadas, porém, sem a conscientização dos estudantes de que em processos educacionais nos quais eles próprios são os principais responsáveis pela aprendizagem, não se alcançará o resultado desejado se não cumprirem as tarefas que são de sua responsabilidade. Em processos ativos de aprendizagem o foco se volta para o estudante, enquanto no modelo tradicional o foco do processo educacional está concentrado nas mãos do professor. No estudo de caso, para ser frutuoso, o estudante deve ler o caso e tentar formular sua própria posição antes da aula para poder participar ativamente da discussão em sala. (BOEHRER, 2017). A atividade prévia envolve também a análise do caso. O estudante deve "gastar mais tempo pensando sobre o caso do que lendo" (ELLET, 2008, p. 28). Cabe, portanto, aos estudantes cumprirem seus papéis como sujeitos 
ativos do processo ensino aprendizagem e ao professor o desafio de encontrar estratégias para garantir que as atividades prévias sejam realizadas.

b) Escolha de casos em função dos objetivos de aprendizagem. $\mathrm{Na}$ experiência realizada, o método do Estudo de Caso foi escolhido com dois objetivos. Por um lado, para desenvolver a capacidade de tomada de decisões com base em argumentos racionalmente motivados e, por outro, para aplicar conceitos de determinadas teorias morais (Aristóteles, Kant e Hans Jonas) na discussão de casos. A análise e discussão de situações à luz de teorias éticas é uma das formas de se ensinar ética apontadas por Reis (2007, p. 37). Levando em conta as duas finalidades apresentadas, a escolha dos casos tornou-se tarefa desafiadora. Conforme Golich et al. (2000), a escolha do caso deve ser feita sempre levando em conta o objetivo da aprendizagem. Nesse sentido, a alternativa foi escrever casos ou fazer adaptações de casos já existentes. Optou-se por trabalhar com casos mais curtos que pudessem ser trabalhados em encontros de duas horas. Casos longos normalmente tomam bastante tempo e isso pode ser uma das restrições para o uso do método do Estudo de Caso no ensino (GOLICH et al., 2000, p. 5). Casos mais curtos permitem também que os estudantes venham mais preparados para as aulas, pois, se for necessário, podem retomar o caso mais rapidamente (GOLICH et al., p.15). Como os casos adotados não passavam de uma lauda, inicialmente os estudantes liam o caso individualmente buscando um posicionamento pessoal sobre o problema apresentado e depois passavam a discuti-lo no time buscando uma solução argumentativamente defensável para o problema levantado.

A escolha de um caso para atender as finalidades da aprendizagem pretendidas não se revela tarefa simples para o professor. $\mathrm{Na}$ literatura é possível encontrar inúmeros casos e de diferentes áreas do conhecimento. A maior parte dos casos se encontra em literatura estrangeira, mas no Brasil também já se tem iniciativas significativas de produção e publicação inédita de casos. ${ }^{9}$ Quando, porém, o estudo de caso visa atender a uma finalidade específica de aprendizagem, por vezes não é tarefa simples encontrar um caso adequado. Cabe ao professor fazer uma boa busca, escrever casos inéditos ou ainda fazer adaptações de fatos ocorridos tornando-os objetos de estudo por meio do método de caso. Golich et al. (2000, p.5) afirma que, embora existam inúmeros e excelentes casos já publicados, por vezes, para atender a objetivos de ensino específicos, é necessário fazer adaptações com artigos de jornal, relatos de fatos ocorridos etc. Pelo fato da maioria dos casos disponíveis na literatura serem bastante longos e demandarem um tempo maior para estudos do que o previsto no plano de ensino, nos Estudos de Caso realizados foram feitas adaptações de fatos noticiados tomando-os como objeto de estudo. Com essa estratégia, além da otimização do tempo mediante o estudo de casos mais curtos, também foi facilitada a escolha de casos para atender os objetivos da disciplina em

9 Á Central de Cases da Escola Superior de Propaganda e Marketing (ESPM) disponibiliza mais de 222 casos inéditos, produzidos no Brasil, agrupados em oito áreas de conhecimento. Para acessálos, basta acessar: <http://www2.espm.br/pesquisa/central-de-cases>. 
questão. Não obstante isso, a escolha de casos para atender a objetivos específicos de aprendizagem é um desafio para o professor.

c) Motivação para participar dos estudos de caso. A partir da prática realizada, um dos grandes desafios é fazer com que os estudantes se sintam instigados e motivados para participarem das discussões de casos. Uma das alternativas é trabalhar com narrativas de casos que possuam um toque de arte além da técnica (SILVA; BENEGAS, 2010) ou que tenham relação direta com o contexto profissional dos estudantes. Por motivos já relatados, na experiência realizada os casos foram adaptados pelo professor a partir de fatos noticiados. Embora Silva e Benegas (2010) afirmem que um verdadeiro estudo de caso não possa ser redigido apenas a partir de notícias e artigos, Golich et al. (2000) entendem que o relato de um simples acidente de avião pode tornar-se objeto de um estudo de caso. Pelo fato dos casos utilizados consistirem em adaptações feitas de fatos noticiados e pelo fato de o professor não ter grande experiência na escrita de casos, certamente faltou um toque de arte para torná-los mais atrativos.

Optou-se por casos que refletem situações de contexto real, mas que não têm relação direta com determina área profissional, pois a turma em questão não era constituída por estudantes de um único curso. Como se tratavam de situações de contexto real que dizem respeito a problemas do homem como cidadão do mundo, alguns estudantes chegaram a expressar que eram temas que não lhes interessava muito envolvendo-se nas discussões apenas quando instigados pelo líder do time ou professor. $\mathrm{O}$ trabalho em times permitiu que os próprios colegas cobrassem maior envolvimento e participação de todos os membros do grupo na solução do problema, o que revelou capacidade de liderança por parte de alguns estudantes. Pensar em estratégias de envolvimento dos estudantes e na escolha ou escrita de casos cuja leitura e discussão seja mais atrativa constitui, portanto, um dos desafios do professor que escolhe o estudo de caso como método de aprendizagem.

d) Condução do estudo de caso. Com base na experiência realizada, a condução do estudo de caso revelou-se tarefa desafiadora para o professor por dois motivos. Em primeiro lugar, para assegurar a participação de todos os estudantes nas discussões e, em segundo, para evitar que o professor manifeste seu modo de pensar desencorajando o pensamento autônomo e crítico dos estudantes. Em relação ao primeiro aspecto, cabe ao professor tomar o cuidado para que todos os estudantes participem das discussões e manifestem seu modo de pensar. Sempre há aqueles que falam mais e os que torcem para não precisarem expor seus pensamentos. Cabe ao professor a tarefa de criar estratégias para controlar os que mais pedem a palavra e instigar aqueles que menos falam para gerar um equilíbrio entre esses dois grupos. $\mathrm{Na}$ condução do estudo de caso deve-se criar estratégias para que os estudantes se sintam emocionalmente seguros visando a participação de todos nas discussões (BOEHRER, 2017). Por se tratar de uma turma relativamente grande e para minimizar o risco de alguns alunos não manifestarem suas opiniões, depois da leitura individual da narrativa, a estratégia adotada foi a da discussão do caso nos times oportunizando com que todos pudessem manifestar seu modo de pensar. O líder de cada time também foi orientado a instigar todos os membros a 
manifestarem sua opinião para, somente depois disso, buscarem uma alternativa de consenso. Em momento posterior, o debate foi sempre realizado no grande grupo, oportunidade na qual os times apresentavam suas conclusões e se abria o debate para o confronto de ideias e construção coletiva do conhecimento. Para evitar que sempre os mesmos representantes do time apresentassem as conclusões do grupo, orientou-se que a cada novo estudo de caso outro representante expusesse os argumentos do time. Entretanto, por mais que se tenha criado estratégias para que todos pudessem ter a oportunidade de falar nos times bem como no grande grupo, quando os debates se tornavam acalorados no grande grupo, normalmente as falas ficavam concentradas em apenas parte dos estudantes. Nos dois primeiros estudos de caso optou-se por controlar o debate de modo que mais pessoas manifestassem seu modo de pensar. Porém, com essa estratégia interrompia-se a espontaneidade e a naturalidade do debate. Assim, nos dois últimos estudos de caso optou-se por deixar que o debate fosse acontecendo conforme o interesse e a vontade dos estudantes em manifestarem suas opiniões. Com essa estratégia o debate tornou-se mais rico em ideias, porém, as discussões por vezes se prolongavam evitando com que mais estudantes pudessem se manifestar.

Em relação ao segundo aspecto, acostumado a aulas expositivas e iniciante no método de caso, o professor por vezes acabou manifestando, entre um debate e outro, o seu modo de pensar sobre o caso aos estudantes. Conforme Ellet, (2008, p.19), no método de caso o professor não deve manifestar seu ponto de vista em relação ao caso. Ele tem de ser um estrategista e adotar a postura socrática de fazer as perguntas certas nos momentos certos para que os próprios estudantes cheguem ao resultado esperado. Ao manifestar seu modo de pensar, mesmo que seja para compartilhar seu conhecimento sobre o assunto, o professor acaba inibindo a autonomia e o pensamento crítico dos estudantes.

e) Reconhecimento do que são bons argumentos por estudantes. Outro desafio que se evidenciou com a prática do método de caso foi a dificuldade de alguns estudantes entenderem quando se está frente a um bom argumento. Influenciados por posturas próprias do senso comum, em geral dogmáticas ou relativistas, no método de caso tem-se o desafio de fazer com que os estudantes entendam a diferença entre um bom e um mau argumento. Tomando-se como base o pensamento de Habermas (1989), em questões éticas um bom argumento é aquele passível de ser aceito por todos os possíveis concernidos, sendo que os argumentantes da roda real de comunicação devem ser capazes de assumir as posições dos possíveis afetados não presentes no debate em busca da melhor alternativa de ação possível. Diante de um dilema ético, por exemplo, estudantes e professor devem se colocar no lugar de todos os possíveis afetados e buscar a melhor alternativa de ação, que é aquela passível de ser aceita universalmente. Nas palavras de Habermas (1989, p. 86) "uma norma [ética] só deve pretender validez quando todos os que possam ser concernidos por ela cheguem (ou possam chegar), enquanto participantes de um Discurso prático, a um acordo quando à validez dessa norma". Assim, a melhor argumento em favor de uma decisão ética é aquele que pode ser aceito por todos os possíveis concernidos. 
A afirmação de que "para mim este é o melhor argumento" sem se colocar no lugar de qualquer um dos possíveis afetados do caso e sem se despir da sua condição real para tomadas de decisões éticas que envolvem terceiros leva, sem dúvida alguma, a posicionamentos parciais, interesseiros e, consequentemente, não universalizáveis. Numa discussão sobre dilemas éticos, o problema não está em definir "se vamos fazer isso ou aquilo, mas que isso ou aquilo seja a coisa correta a fazer, ou a melhor ou a única" (WHITE apud HABERMAS, 1989, p. 72). Em outras palavras, numa discussão de caso sobre questões éticas o problema não está em definir o que cada estudante faria, mas em buscar, por meio de uma argumentação racionalmente motivada, uma resposta objetiva sobre o que de fato é o melhor a ser feito levando em conta as circunstâncias apresentadas. Argumentar em favor de determinada alternativa de ação como sendo a mais justa e adequada sob o ponto de vista ético consiste em apresentar evidências de que aquela alternativa não representa impacto negativo algum ou representa o menor impacto para os possíveis concernidos. Enquanto se tiver alternativas de ação menos impactantes, isto é, menos prejudiciais aos possíveis concernidos, os argumentantes da roda real de discussão (estudantes e professor) têm de ser capazes de assumir uma postura de humildade intelectual e se render ao melhor argumento.

$\mathrm{Na}$ análise de um caso, identificada a questão principal, cabe aos interlocutores se colocarem no lugar do protagonista da narrativa e levantar hipóteses para solucionar o problema. As hipóteses jamais estão erradas (ELLET, 2000), mas isso não significa que elas resolvem o problema de modo satisfatório. A hipótese para a qual não se pode conferir um argumento sustentável não atinge seu objetivo e, por isto, deve ser refutada por meio de análises argumentativas cuidadosas. As hipóteses levantadas num estudo de caso não são certas nem erradas (ELLET, 2000), mas serão refutadas pelos interlocutores do caso se não puderem ser sustentadas com base em evidências: "Uma hipótese que não possa ser sustentada a partir de evidências contidas no respectivo caso não passa de uma opinião sem qualquer fundamento" (ELLET, 2008, p. 35). Mesmo que nos estudos de caso não se tenha uma resposta certa, é possível sempre identificar-se respostas claramente erradas e isto por si só já constitui um sucesso no que diz respeito ao ensino da ética (REIS, 2007, p. 40). Nos estudos de caso nem todos os argumentos são válidos ou sustentáveis. Cabe, portanto, aos estudantes, com o auxílio do professor, assumirem um compromisso com a verdade e buscarem unicamente argumentos com base em boas razões, ou seja, argumentos sustentáveis por todos os possíveis interlocutores.

f) Avaliação da aprendizagem no estudo de caso. O sistema de avaliação no método do estudo de caso muda radicalmente se comparado ao modelo tradicional baseado em aulas expositivas. Se no modelo tradicional o estudante é avaliado pela capacidade de compreender e reproduzir informações em torno de determinado tema, no método de caso o estudante deve ser avaliado pelo seu desempenho nas diferentes etapas do estudo de caso, que vai desde a atividade prévia até a sua participação nos debates em sala. Segundo Golich et al. (2000), a participação em sala deve levar em conta o falar (apresentação de ideias, observações, análises, opiniões, perguntas e respostas aos comentários de outros estudantes) e o 
ouvir (capacidade de acompanhar o que os outros têm a dizer, seguir argumentos e lembrar pontos importantes já destacados). A avaliação no estudo de caso não se dá por meio de um teste ou prova, mas se dá ao longo das aulas, o que exige muito mais do professor. Para minimizar a influência da subjetividade nesse processo, Golich et al. (2000) recomenda o uso de rubricas, tanto para a avaliação da leitura prévia quanto para a participação dos estudantes nos debates sobre o caso. Em relação à participação em sala, além da avaliação do professor, o autor sugere também o uso de um instrumento para realização da avaliação em pares (GOLICH et al., 2000). Na prática realizada, a avaliação se deu a partir de registros diários do professor sobre as participações dos estudantes nos debates, avaliação por pares e produções sintéticas sobre as conclusões do time acerca do caso em discussão. Não obstante isso, percebeu-se a falta de um sistema de avaliação mais elaborado, com rubricas específicas para cada etapa do estudo. Nesse sentido, a construção de um sistema adequado de avaliação é um dos grandes desafios do professor que adota o estudo de caso como método de aprendizagem.

Com base na experiência de sala realizada, estes são alguns dos desafios do professor identificados com a aplicação do estudo de caso como método de aprendizagem. Alguns deles certamente provêm da falta de uma maior experiência por parte do professor responsável pela aplicação da metodologia, mas servirá como norte para que outros docentes interessados na utilização do estudo de caso como método de aprendizagem possam se guiar. Outros desafios apresentados certamente provêm da especificidade da disciplina na qual o método foi aplicado, pois, enquanto os resultados das discussões de casos ligados à área de negócios podem representar insucessos profissionais futuros, caso os estudantes não se guiarem por argumentos racionalmente motivados para sustentar determinada posição, os resultados das discussões de casos na área da ética podem representar conivência com situações de injustiça. Tomadas de decisões éticas, avalizadas por sujeitos descompromissados com a verdade e a dignidade humana no exercício de sua profissão, podem trazer consequências irreparáveis para indivíduos, grupos sociais ou até mesmo gerações inteiras. Não obstante isso, os estudos de caso devem ser levados muito a sério independentemente do tema e área contemplada, pois, como se trata de antecipações de recortes do mundo real, os resultados profissionais futuros podem ser nefastos quando os interlocutores da roda do discurso não assumem desde já o compromisso de se guiarem sempre pelos melhores argumentos.

\section{Consideraçóes finais}

A presença da disciplina de Ética na matriz curricular por si só não garante qualidade na formação humanística dos estudantes. Mais do que simplesmente dominar e compreender conceitos de ética, o estudante precisa aprender a aplicálos a situações de contexto real. Mediante análises e reflexões, precisa aprender a buscar alternativas de ação em situações controversas que sejam boas ou menos impactantes para todos os possíveis concernidos. Esse nível cognitivo só é alcançado por metodologias que coloquem o estudante no centro do processo ensino 
aprendizagem. É dentro desta perspectiva que o estudo de caso se apresenta como alternativa interessante para a promoção da aprendizagem ativa dos estudantes.

No método do estudo de caso o professor atua como um estrategista para fazer com que os próprios estudantes aprendam a tomar decisões com base em argumentos racionalmente motivados. A partir de narrativas ou dilemas de contexto real os estudantes aprendem a analisar situações, avaliar consequências, ouvir opiniões contrárias, confrontar ideias e sustentar hipóteses buscando as melhores alternativas de ação para o problema apresentado. Não obstante isso, a aplicação do estudo de caso como método de aprendizagem aos estudantes apresenta diversos desafios ao professor, principalmente quando este e a turma na qual vai ser aplicado estão acostumados a aulas predominantemente expositivas. A partir da prática realizada numa disciplina de Etica no nível de graduação foram destacados diversos desafios, que vão desde a motivação dos estudantes para realização de atividades prévias até a avaliação da aprendizagem por meio método de caso.

Para estudantes acostumados a aulas tradicionais, garantir a realização de atividades prévias torna-se um desafio para o professor, pois, sem elas, o desenvolvimento de atividades em sala de aula fica comprometido. A escolha de casos tendo em vista os objetivos de aprendizagem e que ao mesmo tempo motivem a participação efetiva dos estudantes também revelam-se como desafios para o professor. A condução do estudo de caso visando a participação e o envolvimento de todos os estudantes bem como a respectiva capacidade de distinguir entre bons e maus argumentos, principalmente no que se refere a dilemas éticos, constituem outro par de desafios apontados a partir da prática realizada. E, por último, a avaliação da aprendizagem com critérios claros e objetivos no que diz respeito à aplicação do estudo de caso também constitui um grande desafio ao professor que adota o estudo de caso como método de aprendizagem.

Por mais que estudo de caso represente alguns desafios ao professor, sua aplicação permite trabalhar com situações de contexto real para que os estudantes aprendam a tomar decisões buscando sempre fundamentar seu agir com base em argumentos racionalmente motivados. Com os debates promovidos em sala de aula os estudantes têm a oportunidade para aprender a lidar com situações complexas podendo validar suas conclusões por meio do olhar atento e crítico dos colegas de turma e professor. O estudo de caso permite antecipar situações complexas do mundo real fazendo com que o estudante aprenda a avaliar as consequências de suas escolhas sem de fato sofrer o impacto de possíveis conclusões equivocadas. Caso obtenha êxito com seus interlocutores em suas argumentações apresentadas, saberá que está no caminho certo; caso não obtenha êxito, terá oportunidade de aprender com seus interlocutores e se preparar melhor para tomadas de decisões futuras. 


\section{REFERÊNCIAS}

ARISTÓTELES. Ética a Nicômacos. 3. ed. Brasília: Editora da UnB, 1992.

BOEHRER, John. Learning by the Case Method. Kennedy School of Government Case Program. Disponível em: <http://case.hks.harvard.edu/content/1136_0.pdf>. Acesso em: 23 ago. 2017.

ECHEVERRÍA-FALLA, Cecilia. Educación ética: normas o virtudes? Qué giro debe tomar la enseñanza de la ética en la formación de universitarios solidarios? Persona e Bioética, vol. 17, n. 2, p. 151-167, jul./dic.2013.

ELLET, William. Manual de Estudo de caso: como ler, discutir e escrever casos de forma persuasiva. Porto Alegre: Bookman, 2008.

FERRAZ, Ana Paula do Carmo Marcheti; BELHOT, Renato Vairo. Taxonomia de Bloom: revisão teórica e apresentação das adequações do instrumento para definição de objetivos instrucionais. Gest. Prod., São Carlos, v. 17, n. 2, p. 421-431, 2010.

GOERGEN, Pedro. Educação moral: adestramento ou reflexão comunicativa? Educaçao \& Sociedade, Campinas, ano XXII, n. 76, p. 147-174, out. 2001.

GOLICH, Vicki L. et al. The ABCs of Case Teaching: Pew Case Studies in International Affairs. [S. n.: s. 1.], 2000. Disponível em: <https://pt.scribd.com/ document/229836112/ABCs-of-Case-Teaching >. Acesso em: 23 ago. 2017.

GÓMEZ, Verónica; ROYO, Paulina. Autodescubrimiento ético y deliberación: Hacia un modelo de enseñanza de la ética en el modelo por competências. Estudios Pedagógicos, vol. 41, n. 2, p. 345-358, 2015.

HABERMAS, Jürgen. Consciência moral e agir comunicativo. Rio de Janeiro: Tempo Brasileiro, 1989.

JULIATTO, Clemente Ivo. O horizonte da educação: sabedoria, espiritualidade e sentido da vida. Curitiba: Champagnat, 2009.

PAVIANI, Jayme. A dimensão ética da educação. In: MARCON, Telmo (Org.). Educação e Universidade: práxis e emancipação. Passo Fundo: Ediupf, 1998. p. 385-398.

REALE, Giovanni; ANTISERI, Dario. História da Filosofia. São Paulo: Paulinas, 1990. Vol. 1.

REIS, Pedro. O ensino da ética nas aulas de ciências através do estudo de casos. Interacções, [S.1.] n. 5, p. 36-45, 2007.

SILVA, Robesval Ribeiro da; BENEGAS, Alexandre Albertini. O uso do estudo do caso como método de ensino na graduação. Economia \& Pesquisa, Araçatuba, v.12, n.12, p. 9-31, nov. 2010. 
PONTE, João Pedro da. Investigar a nossa própria prática. In: GTI (Org). Reflectir e investigar sobre a prática profissional. Lisboa: APM, 2002. p. 5-28.

PONTIFÍCIA UNIVERSIDADE CATÓLICA DO PARANÁ - PUCPR. Princípios orientadores do processo de ensino e aprendizagem. [S.n.: s.l.], 2014.

ZETINA-ESQUIVEL, Erick Ivanovic; PIÑÓN-RODRÍGUEZ, Patricia Dolores. El método socrático en los programas educativos actuales: una propuesta de Martha C. Nussbaum. La colmena, [S.1.], n. 91, p. 79-90, oct. 2017. 